\title{
Characterization of the Stem Cell Fraction in Pancreatobiliary Carcinomas: The Notch Signaling Pathway as a Potential Therapeutic Target
}

\author{
Elisabeth Seidel*, Cynthia de Carvalho Fischer, Christopher Neumann, Anja Reutzel-Selke, \\ Andreas Andreou, Joseph Gassner, Julia Gogolok, Peter Tang, Anja Schirmeier, Fritz Klein, \\ Igor M. Sauer, Johann Pratschke, Marcus Bahra, Rosa B. Schmuck
}

Charité-Universitätsmedizin Berlin, Corporate Member of Freie Universität Berlin, Humboldt-Universitätzu Berlin, and Berlin Institute of Health, Institute of Surgery, Augustenburger Platz 1, Berlin, Germany

Email: *elisabeth.seidel@charite.de

How to cite this paper: Seidel, E., de Carvalho Fischer, C., Neumann, C., Reutzel-Selke, A., Andreou, A., Gassner, J., Gogolok, J., Tang, P., Schirmeier, A., Klein, F., Sauer, I.M., Pratschke, J., Bahra, M. and Schmuck, R.B. (2018) Characterization of the Stem Cell Fraction in Pancreatobiliary Carcinomas: The Notch Signaling Pathway as a Potential Therapeutic Target. Journal of Cancer Therapy, 9, 480-502. https://doi.org/10.4236/jct.2018.96040

Received: April 15, 2018

Accepted: June 5, 2018

Published: June 8, 2018

Copyright (๑) 2018 by authors and Scientific Research Publishing Inc. This work is licensed under the Creative Commons Attribution International License (CC BY 4.0).

http://creativecommons.org/licenses/by/4.0/

(c) (7) Open Access

\begin{abstract}
Pancreatic adenocarcinoma (PDAC) and extrahepatic cholangiocarcinoma (ECC) are highly lethal malignancies with limited treatment options. Both a small subpopulation of cancer stem cells (CSC) and the deregulation of the notch pathway have been considered potential sources of tumor formation. In this study, flow cytometry (FCM) was conducted to identify the CSC population and Notch-associated proteins in ECC and PDAC cell lines. Additionally, the treatment effect of Gemcitabine and the specific notch-inhibitor DAPT on ECC and PDAC cell lines was evaluated. Our results show that the amount of SP cells in ECC cell lines is significantly higher than in PDAC cell lines, and that SP-ECC cells show a higher sensitivity to therapy. In conclusion, inhibition of Notch signaling with DAPT may be of therapeutic value in ECC, but seems to show no effect on more aggressive PDAC. As it could be essential for the improvement in outcomes of the ECC patients, other trials are needed to determine the role of further Notch components.
\end{abstract}

\section{Keywords}

Notch Pathway, Cancer Stem Cells, Pancreatic Adenocarcinoma, Extrahepatic Cholangiocarcinoma, Targeted Therapy

\section{Introduction}

Pancreatic ductal adenocarcinoma (PDAC) and extrahepatic cholangiocarcino- 
ma (ECC) are aggressive tumors that display an increasing incidence and high mortality rates [1] [2] [3].

Successive genetic mutations in epithelial cells of both ductal systems lead to corresponding precursor lesions such as pancreatic intraepithelial neoplasm (PanIN) and the biliary intraepithelial neoplasia (BilIN) [1] [2] [4]. The step-by-step progression of these neoplastic lesions finally leads to a malignant transformation [1] [2] [4].

Distal cholangiocarcinoma (dCC) is a subtype of extrahepatic cholangiocarcinoma, which develops from the distal bile duct. The differentiation of this neoplastic entity from ductal adenocarcinomas arising from the head of pancreas is complex, due to their anatomical proximity and their overlapping histopathological and morphological appearance [5].

For both entities, the only curative therapy remains radical surgical resection [2] [3]. The prognosis of PDAC and dCC patients after R0 resection differs in 5 years overall survival rates of $15 \%-20 \%$ for PDAC and $27 \%-30 \%$ for dCC [2] [3]. In cases deemed unresectable, first-line chemotherapy consists of a combination of Gemcitabine and cisplatin for ECC whereas standard of care for PDAC consists of Gemcitabine, FOLFIRINOXor Gemcitabinein combination with Taxanes such as nab-Paclitaxel [6] [7]. Although life expectancy could be improved with those therapeutic approaches, in light of the poor prognosis of these cancer types, as well as the lack of curative success that has been achieved through the use of conventional chemotherapeutics, it is necessary to focus on the development of new treatment targets and regimens for these neoplasms.

In an increasing number of tumor entities, cancer stem cells (CSC) have been discussed as a potential new therapeutic target. In opposition to the stochastic tumor model which supposes that carcinomas are homogenous masses of highly proliferating cells, the CSC concept postulates both cellular diversity and hierarchy in solid tumors [8]. A small subpopulation with stem cell-like characteristics, which may initiate tumor cell growth and survival, has been described to co-exist with the stromal cell compartment and a variety of immune and cancer cells [8] [9]. CSCs display a potential for migration and self-renewal, which in turn increases the risk for metastasis and tumor relapse after therapy [8] [9]. Furthermore, CSCs are said to be responsible for the chemotherapeutical resistance of tumors due to their influence on the cell cycle and the presence of efflux transporters [8]. These so-called ATP binding cassette channel transporters are capable of expelling fluorescent HOECHST-dye, thus allowing their detection through flow cytometry (FCM). Previous publications have hypothesized that the morphologic and functional characteristics of CSCs may determine both the degree of malignancy and likelihood of treatment failures [8]. Thus further understanding of deregulated molecular mechanisms in CSCs may enable the development of targeted therapies that will advance the quality of life and survival of cancer patients [9].

Recent investigations point toward an important role for the Notch signalling pathway in inducing the activation of CSCs. In the adult organism, notch-associated 
proteins influence diverse cellular processes, such as proliferation, apoptosis, differentiation, angiogenesis, migration and adhesion [10]. The activation of the notch signaling pathway during embryonic development leads to the repression of further differentiation processes in neuronal, stromal, cardiac and vascular precursor cells [10]. With respect to the pancreas and the biliary tree, notch signaling increases the proliferation of pancreatic progenitor cells and inhibits the recruitment of exo- and endocrine cells from the stem cell pool [10] [11] [12]. Similarly, the deregulation of the notch pathway seems to play a key role in the formation of neoplasms such as PanINs and the tumorigenesis of various carcinomas [10] [11].

The following study intended to achieve two primary goals: Firstly, we aimed to describe the CSC fraction in PDAC and ECC cell lines, in an attempt to further characterize the biomolecular features of both tumor entities. Secondly, we investigated whether notch-associated proteins are deregulated in PDAC and ECCCSCs in vitro and sought to determine the efficacy of a pharmacological Notch signaling inhibition using a gamma secretase inhibitor (DAPT). Furthermore, we examined the effect of the widely used chemotherapeutic drug, Gemcitabine, on the subset of CSCs. Thus, this study evaluates the relevance of the notch pathway as a potential new target in ECC and PDAC, while seeking to compare its efficacy with an established chemotherapeutic drug, Gemcitabine.

\section{Results}

\subsection{The Proportion of Side Population (SP) Cells and Notch Pathway Components Varies in PDAC and ECC Cell Lines}

To investigate whether CSCs are present in PDAC and ECC cell lines, side population (SP) sorting via flow cytometry was performed.

The mean percentages of SP cells in ECC cell lines were $3.83 \pm 0.45$ SEM $(2.1 \%$ - 5.1\%) and $1.68 \pm 0.12$ SEM in PDAC cell lines (1.1\% - 2.1\%, Figure 1(a)). Thus, ECC cell lines showed a significantly higher proportion of SP cells than

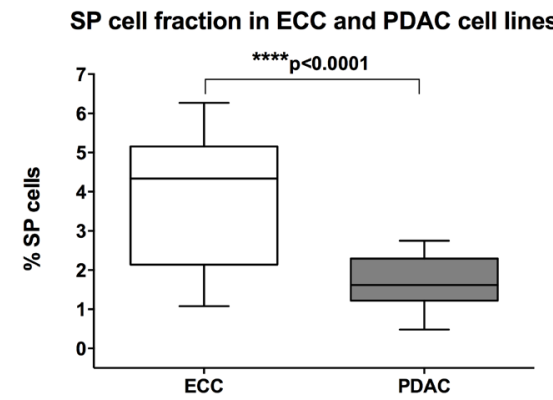

(a)

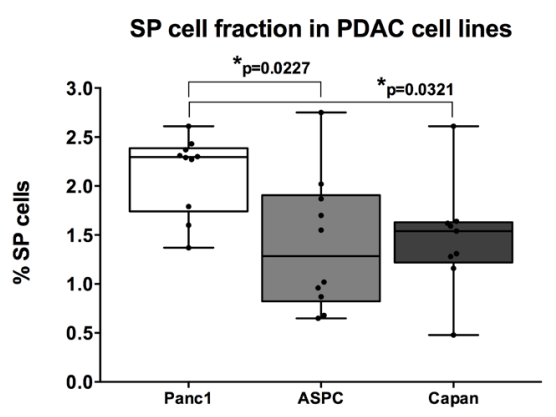

(b)

Figure 1. (a) SP cell proportion of ECC and PDAC cell lines. ECC cell lines $(n=13)$ show a significant higher proportion of SP-cells than PDAC cell lines $(n=29)$. Data represented as mean \pm SEM; (b) SP cell proportion of PDAC cell lines. Panc1 $(n=11)$ presents the highest percentage of SP cells, followed by ASPC $(n=10)$ and Capan $(n=9)$. Data represented as mean \pm SEM. 
PDAC cell lines $(\mathrm{p}<0.0001)$. In addition, SP cell fractions vary significantly between the different PDAC cell lines: Panc1 (M 2.13 \pm 0.13 , SD 0.40) presents a higher percentage of SP cells than ASPC $(\mathrm{M} 1.41 \pm 0.22$, SD 0.69, p = 0.02) and Capan (M 1.47 \pm 0.19, SD 0.56, p = 0.03, Figure $1(\mathrm{~b})$ ).

Based on the observation that SP cells do exist in ECC and PDAC cell lines, we investigated the activation of the Notch pathway in this subpopulation. To determine and compare the expression of Notch pathway components in SPand Non-SP fractions of ECC and PDAC cell lines, antibody staining was conducted and measured by flow cytometry.

Our findings show that Notch-associated proteins are present in the SP fractions of ECC and PDAC cell lines (Table S1). Nevertheless, we could not reveal a significant up-or down-regulation of the examined notch-associated proteins in SP compared to Non-SP cells.

The presence of notch-associated proteins varies between PDAC and ECC cell lines. In PDAC cell lines, Panc1 expresses a high amount of Notch1, Notch4 and Adam17 while Capan and ASPC show only moderate expression of these pathway components. Hes1 and Musashi are poorly expressed in all PDAC cell lines (Table S1). In opposition to that, ECC cell line TFK shows a high expression of Hes1 and Musashi (data not shown). However, we could not prove a significant difference between the expression of these proteins in ECC and PDAC cell lines.

\subsection{The Therapeutic Efficacy of DAPT and Gemcitabine Is Cell Line-Dependant}

A CellToxGreen Assay was performed to measure the viability of PDAC and ECC cell populations following DAPT and Gemcitabine treatment. Additionally, TUNEL staining was used to explore the apoptotic effects of the indicated treatment.

Regarding the effects of Gemcitabine, the CellToxGreen Assay indicated a significant increase of cell death in Panc1 (50, 500 and $1000 \mu \mathrm{M})$ and ASPC (10, 50, 500 and $1000 \mu \mathrm{M}$ ) cell lines (Table S2, Figure 2). Using a TUNEL assay we were able to show a clear increase in apoptotic signaling under Gemcitabine treatment, which we were unable to underpin with a statistically significance. In cell line Capan, Gemcitabine showed no cytotoxic effect on the total population.

Interestingly, no significant reduction of the EGI cell population was measurable under Gemcitabine treatment. In opposition to that, 50, 100, 500 and 1000 $\mu \mathrm{M}$ of Gemcitabine induced a significant increase in cell death for the TFK cell line (Table S2, Figure 2). TUNEL staining demonstrated similar effects: 1000 $\mu \mathrm{M}$ of Gemcitabine treatment induced the apoptosis in cell line TFK significantly (M 49.71 \pm 16.97, SD 33.94, $\mathrm{p}=0.04)$ but showed no effect on cell line EGI.

During the CellToxGreen experiment, 10 and $50 \mu \mathrm{M}$ of DAPT increased the dead cell signal in cell line ASPC significantly compared to the untreated control. 


\section{Cytotoxic effect of Gemcitabine}
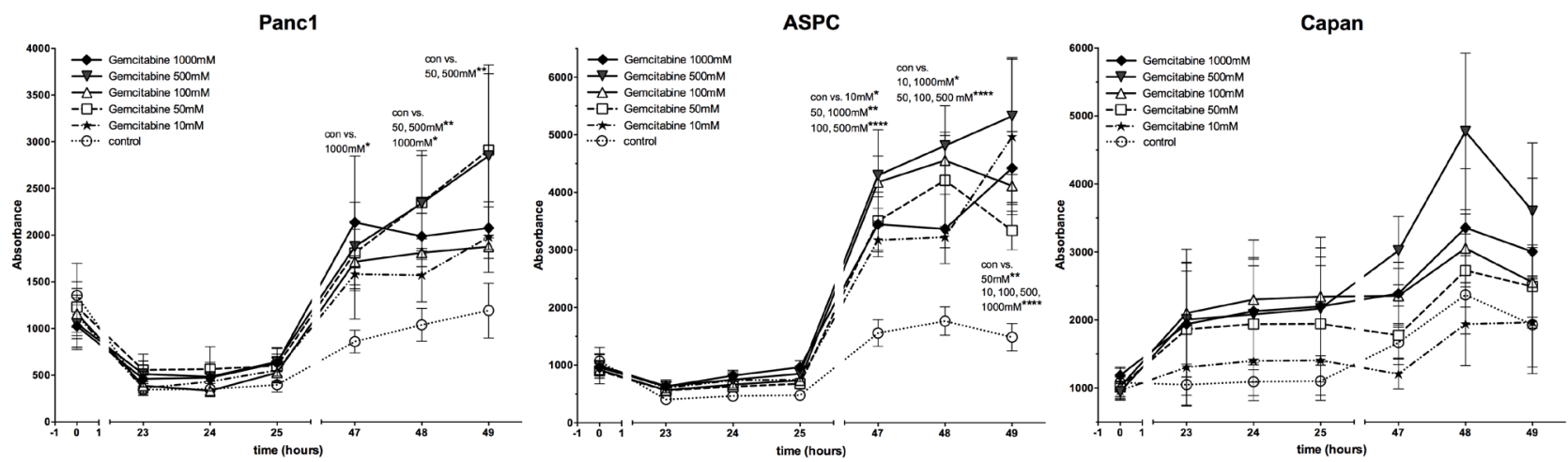

EGI
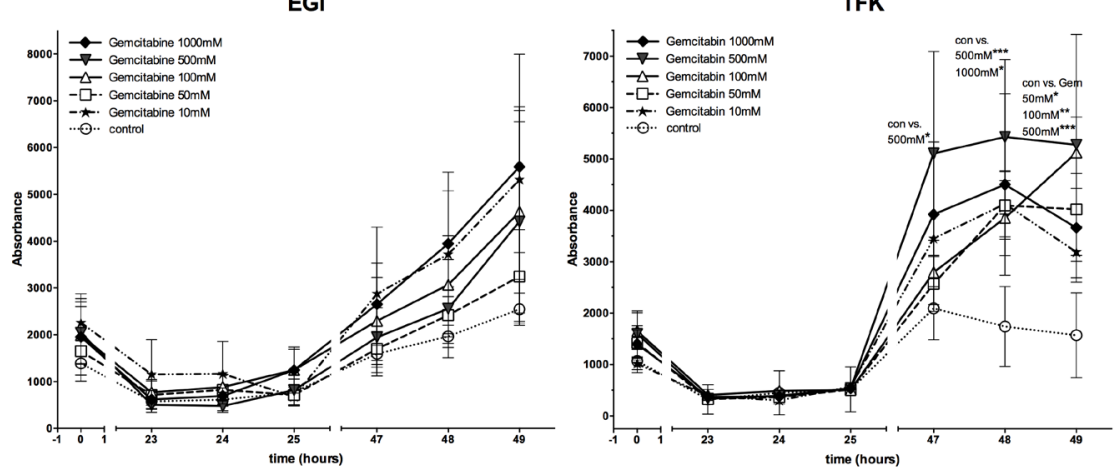

Figure 2. CellTox Green assay of PDAC and ECC cell lines under Gemcitabine treatment. Significant increase of dead cell signal after $47-49 \mathrm{~h}$ in cell lines Panc1, ASPC and TFK under different concentrations of Gemcitabine treatment. Data are represented as mean $\pm \operatorname{SEM}\left({ }^{*}>0.005,{ }^{* *}=0.005-0.001,{ }^{* * *}=0.001-0.0001,{ }^{* * * *}<0.0001\right)$. See also Table S2.

(Table S3, Figure 3). Treatment of PDAC cell lines Capan and Panc1 with DAPT showed no significant cell death.

In opposition to that, ECC cell lines demonstrated a significant increase of cell death when incubated with $5 \mu \mathrm{M}$ DAPT (EGI, Table S3, Figure 3) and $50 \mu \mathrm{M}$ DAPT (TFK, Table S3, Figure 3). Simultaneously, TUNEL staining showed a considerable but not significant increase of apoptosis in EGI (at $50 \mu \mathrm{M}$ DAPT M $32.28 \pm 19.96$, SD 34.58, $\mathrm{p}=0.57$ ) and TFK cell lines (at $50 \mu \mathrm{M}$ DAPT M $27.65 \pm$ 7.12, SD 14.25, p = 0.36, Figure 4(a) and Figure 4(b)).

In conclusion, the cytotoxic and apoptotic effects of DAPT and Gemcitabine differ in PDAC and ECC cell lines. Gemcitabine treatment induces significant cell death in two out of three PDAC cell lines. Cell viability for TFK decreased under Gemcitabine therapy, whereas EGI showed no response.

In opposition to that, DAPT treatment decreases cell viability of both ECC cell lines, and affects only one of the PDAC cell line, namely Panc1.

\subsection{DAPT Reduces SP Cells in ECC Cell Lines, but Shows No Effect on PDAC Cell Lines}

The pharmacological inhibition of the Notch pathway in the SP cells of ECC and 


\section{Cytotoxic effect of DAPT}
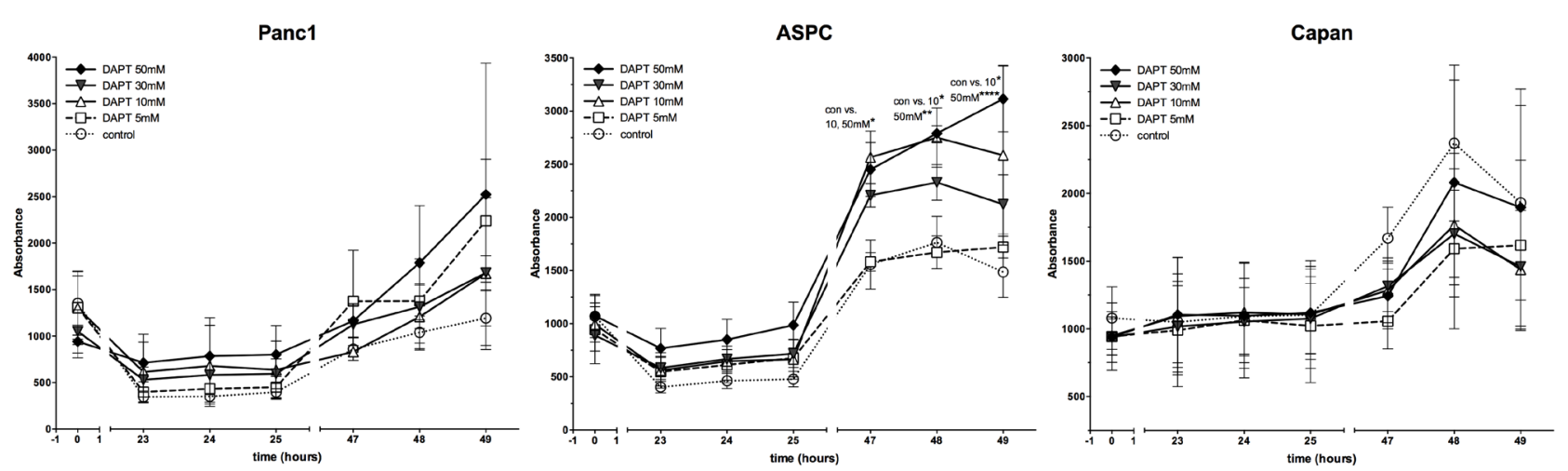

EGI
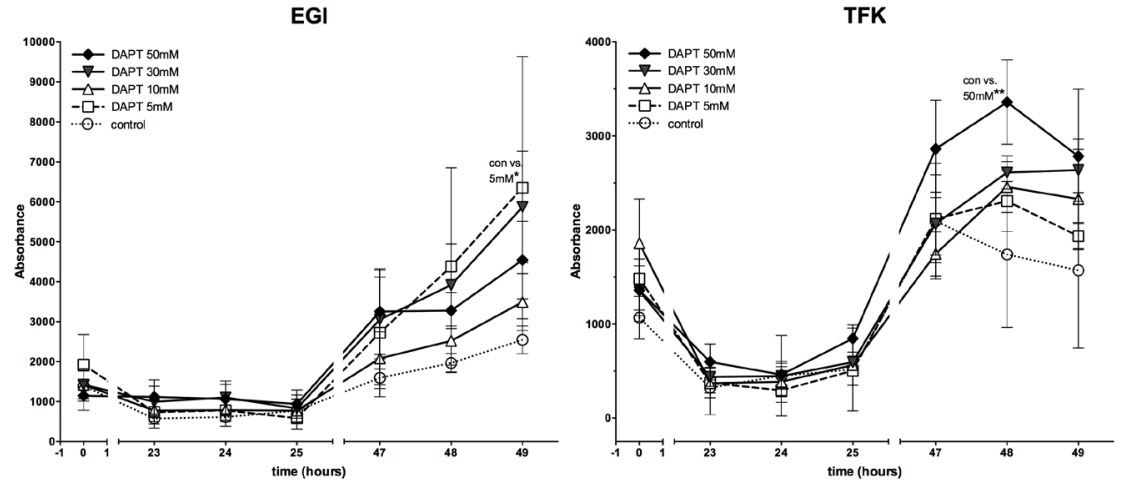

Figure 3. Results of Cell Tox Green Cytotoxity Assay in DAPT-treated PDAC and ECC cell lines. Significant increase of death-cell signal under a therapy with 10 and $50 \mu \mathrm{M}$ DAPT after $47-49 \mathrm{~h}$ in cell line ASPC $(\mathrm{n}=3)$, in cell lines EGI and TFK under $5 \mu \mathrm{M}$ and $50 \mu \mathrm{M}$ DAPT treatment after $48 \mathrm{~h}$ and $49 \mathrm{~h}(\mathrm{n}=4)$. Data are represented as mean $\pm \operatorname{SEM}\left({ }^{*}>0.005,{ }^{* *}=0.005-0.001,{ }^{* * *}=0.001\right.$ $\left.-0.0001,{ }^{* * * *}<0.0001\right)$. See also Table S3.

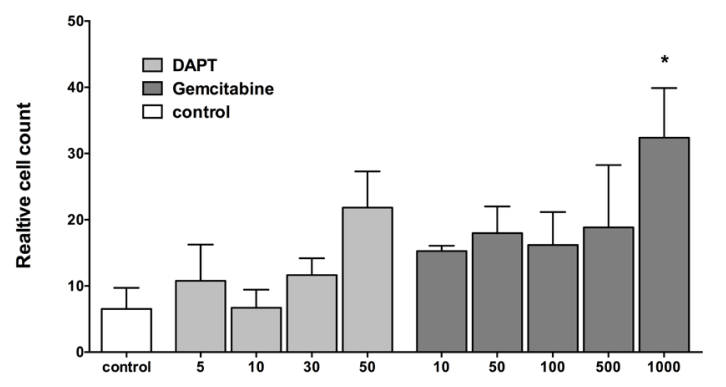

(a)

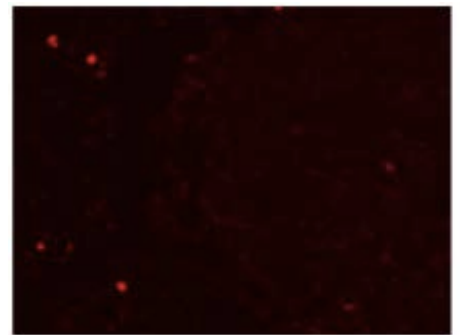

(b)

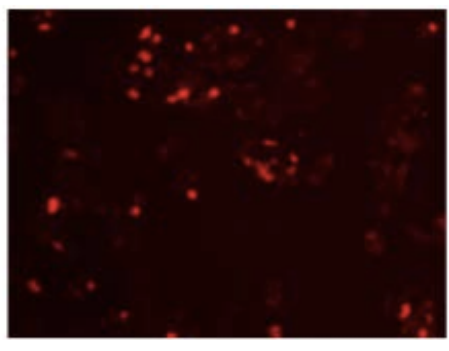

Figure 4. (a) TUNEL assay of ECC cell line TFK. Clear trend in increase of the apoptotic signal under DAPT treatment and significant increase of apoptosis under $1000 \mu \mathrm{M}$ Gemcitabine treatment $(\mathrm{n}=3)$. Data are represented as mean \pm SEM; (b) Qualitative analysis of TUNEL assay of ECC cell line TFK. Left: without treatment and $50 \mu$ M DAPT treatment $($ right $)(n=3)$.

PDAC cell lines was evaluated.

The SP cells of PDAC cell lines demonstrated a different response to the therapy with DAPT and Gemcitabine compared to the SP cells of ECC cell lines. In PDAC cell lines, the only significant decrease of the SP fraction was shown with $50 \mu \mathrm{M}$ Gemcitabine treatment. When considering individual PDAC cell lines, 

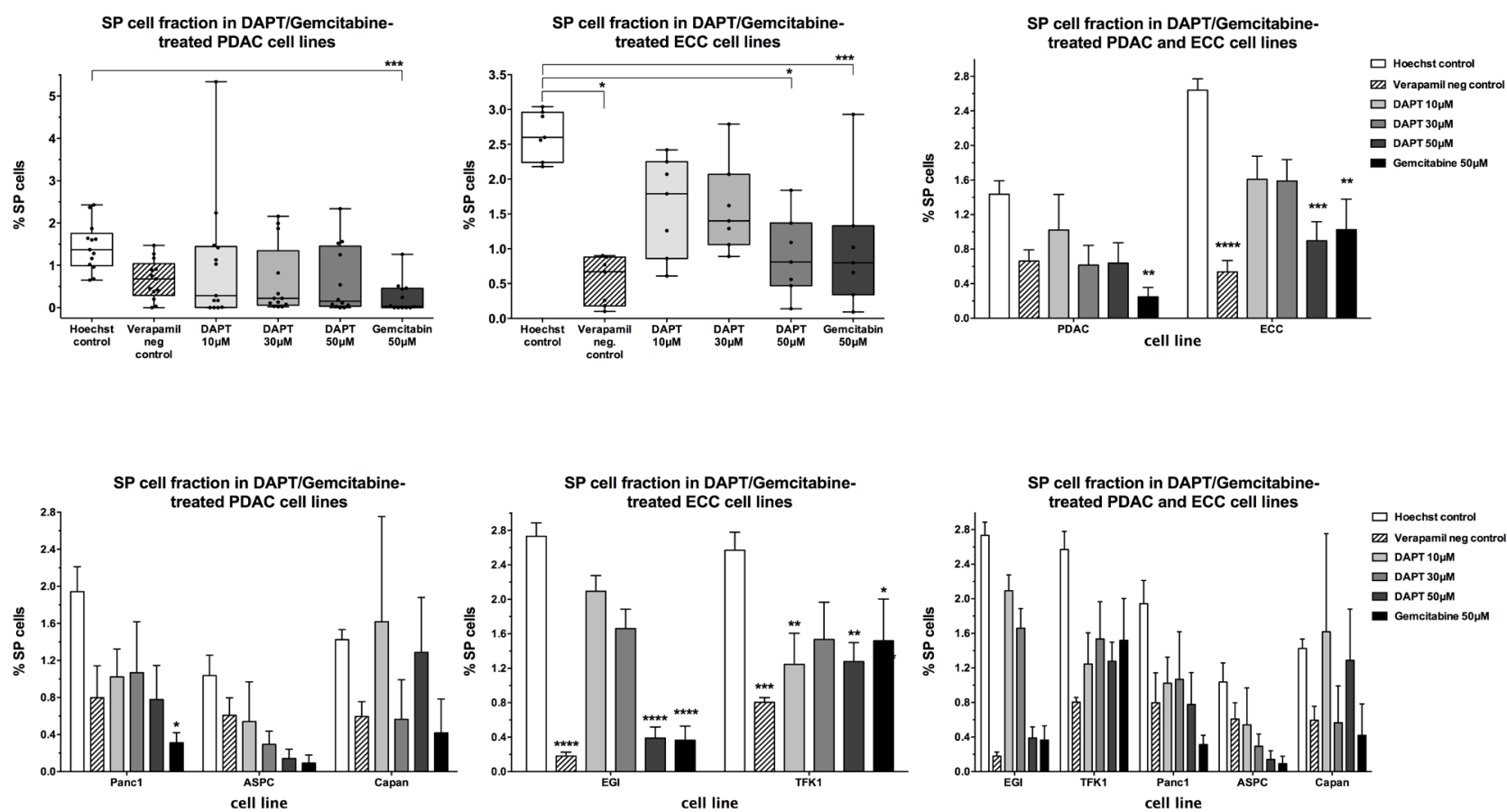

Figure 5. FCM-Analysis of SP cells in ECC and PDAC cell lines. SP cell fractions of both ECC cell lines (EGI, TFK, $n=3)$ lines decrease significantly under DAPT- and Gemcitabine therapy, while DAPT therapy shows no effect on SP fractions of PDAC cell lines $(n=5)$. Data are represented as mean $\pm \operatorname{SEM}\left({ }^{*}>0.005,{ }^{* *}=0.005-0.001,{ }^{* *}=0.001-0.0001,{ }^{* * *}<0.0001\right)$. 
course and life expectancy. The currently available therapies could improve life expectancy remarkably but have shown only limited curative success. Gemcitabine, the backbone of chemotherapeutic approaches in both entities has been shown to be an effective strategy both in adjuvant and palliative setting [13]. FOLFIRINOX, an alternative regimen consisting of 5-FU/leucovorin, oxaliplatin and irinotecan showed promising results in advanced pancreatic cancer prolonging median overall survival up to 11.1 month even in palliative setting [6].

Novel therapeutic regimens, where Gemcitabine was used in combination with Erlotiniband Nab-Paclitaxel, could also substantially improve survival in palliative cases [7]. Ongoing studies such as APACT (adjuvant therapy for pancreatic cancer trial: Gemcitabine plus Nab-Paclitaxel) and the French ACCORD/ PRODIGE study (modified FOLFIRINOX regimen) which are actively recruiting hold out the prospect of improving current gold standard therapy in PDAC also for adjuvant therapy. Neoadjuvant approaches with promising first results need to be evaluated further in lager clinical trials but could change the current treatment paradigm [14].

Further exploration of ECC and PDAC tumor biology, with emphasis on what differentiates these tumor entities, may lead to the development of more specific and effective therapeutic regiments. However, this subject remains largely unexplored [5]. Therefore, this experimental study focuses on the relevance of CSCs and Notch pathway components in both ECC and PDAC cell lines, and whether ECC and PDAC differ in respect to these biological pathways.

In this study, FCM analysis indicated that CSCs are present in all ECC and PDAC cell lines. The examined cell lines differ significantly in their SP cell fractions, whereby ECC cell lines reveal a significantly higher percentage of SP cells than PDAC cell lines. Thus, CSCs could function as an additional factor in differentiating PDAC and ECC tumors. Nevertheless, further investigations are required to identify further biological traits that will help precisely define and differentiate both tumor entities.

The results of our FCM analysis exposed no significant deregulation of Notch-associated proteins in the CSC subpopulations of PDAC and ECC cell lines, as compared to Non-SP cells. A major limitation of this study the limited focus on only five antigens out of a huge range of Notch-associated proteins, which may have distinctive roles in tumor progression. Previous publications mentioned the activation and presence of Notch-associated proteins Notch 3 [15], Jagged 2 [16], DLL 3 [16] and DLL4 [16] [17] in human pancreatic tumors. Therefore other proteins may play a more important role in the Notch mosaic, which needs to be explored further.

The studies of Plentz et al. confirmed a lack of the Notch pathway component Hes1 in undifferentiated pancreatic tumors, as opposed to a strong expression of this target in well-differentiated PDACs [15]. These findings suggest that the expression of Notch-associated proteins is subject to strong variations within the same tumor type. It is possible that this variation may also extend to cell lines. 
Additionally, it has been postulated that Hes1 [15] [18] and Notch 2 [18] are expressed in PanINs, but not in the cell lines used in our study. Different developmental stages of PDACs thus may show different expression levels of notch-associated proteins. This aspect could not be addressed in our in vitro set up.

It is noteworthy that the Notch-pathway is only one puzzle piece in a complex network of signaling pathways that contribute to tumor biology. Other important embryological signaling pathways include Wnt and Hedgehog [19] [20]. To improve our understanding of the Notch signaling cascade and its functional role in tumor formation, we explored the inhibition of this pathway through the gamma secretase inhibitor DAPT. Furthermore, the effect of Gemcitabine and DAPT on CSCs was investigated in order to explore potential mechanisms of treatment failures in PDAC and ECC.

We found that the influence of DAPT and Gemcitabine therapy on ECC and PDAC cell lines differs. Moreover, the therapeutic responses of the SP cells can be distinguished from the response of the complete ECC and PDAC cell populations. Within 49 hours, DAPT decreased the amount of SP cells in ECC cell lines and showed a cytotoxic effect on the entire ECC population. The findings of El Khatib et al. confirm and complete these results, demonstrating the reduction of cell viability, proliferation, migration, invasion and colony forming of EGI and TFK cell lines under GSI-IX (gamma-secretase inhibitor) therapy [21].

In contrast, SP cells in PDAC cell lines seem to be refractory to treatment with DAPT. Nonetheless, DAPT shows a significant cytotoxic effect on the overall ASPC cell population. The effect of Gemcitabine on the SP cell fraction of PDAC cell lines is limited to one cell line, Panc 1, which remarkably shows a significant decrease in the percentage of SP cells after treatment.

In conclusion, combined Gemcitabine and DAPT therapy is most efficient in cell lines with relatively large SP fractions. Therefore, it is possible that the CSCs of individual tumors vary in their malignancy and aggressiveness. This result highlights the need for personalized tumor treatments, and suggests that CSCs could be considered a potential therapeutic target.

In summary, our study suggests that PDAC cell lines show higher treatment failure than ECC cell lines in vitro. These results are also reflected in the outcome and 5-year survival rates of ECC and PDAC patients [2] [3]. The increased resistance of CSCs in PDAC cell lines offers an explanation for higher recurrence rates of PDAC in clinical cohorts.

The most important limitation of this study is the utilization of cell lines, which do not provide an accurate model for the pathophysiology of PDAC due to the lack of a 3D structure that allows for interactions with the extracellular matrix and stromal tissue components, as well as the host immune system. Immunohistological studies of primary PDACs revealed that a strong Hes1 expression correlates to a poor outcome in pancreatic adenocarcinoma patients [22]. The investigation of Notch signalling proteins in these tumor types should thus 
be extended to primary tumor tissue and further correlated to clinical outcome. Sucha study would further clarify your understanding of the similarities and differences between these tumor types with respect to the Notch-signalling. The abovementioned methods allow a short insight into a complex molecular process. DAPT may induce a variety of effects besides the induction of apoptosis and general cytotoxicity. It has also been postulated that DAPT influences the activation of the adapted immune system, which could have various effects on tumorigenesis [15] [23] [24]. Mullendore et al. demonstrated that Panc1 and Capancell lines GSI-18 therapy leads to a significant reduction of colony formation in soft agar although no significant diminution of cell growth and viability could be shown [16]. Cook et al. report that the anti-vascular effects of GSI MRK 003 lead to hypoxic necrosis in mouse tumors, an effect that was not detectable in cell lines [25]. However, hypoxic effects and the formation of necrosis are difficult to reproduce in in vitro setting.

This study examines the short-term effects of Gemcitabine and DAPT on ECC and PDAC cell lines up to 49 hours after treatment. Recurrence of tumor cells is one characteristic for malignancy, which the SP population said to be responsible for [8] [26]. Nevertheless, long-term effects of Gemcitabine and DAPT on the SP population could not be evaluated in present experimental set up. Several studies have indicated that Gemcitabine leads to an effective inhibition of PDAC tumor growth during the initial phase of treatment, but tumor cells seem to recover after the elimination of the chemotherapeutic [22] [26]. Lee et al. showed that pancreatic cancer cell lines (BxP3 and HPAC) treated with Gemcitabine were able to recover from initial treatment and massive cell death, and achieve $80 \%$ confluence 3 - 4 weeks after treatment [22].

From a clinical point of view, it is noteworthy that other gamma secretase inhibitors (for example MK-0752 [27], MK-003 [15], RO4929097 [28], PF-03084014 [29]) have already been explored in Phase I trials of patients with solid tumors [27] [28] [29]. Notch-signaling inhibition has shown no treatment benefit in a clinical context so far, due to the mixed response rates of tumors and the challenges presented by highly dose-dependent drug toxicities, primarily leading to gastrointestinal side effects [27] [28] [29]. Our study should be understood as an additional trial to investigate the Notch signaling inhibition as a specific CSC-targeted therapy.

In conclusion, our preclinical findings suggest that the Notch pathway may constitute a promising molecular target, harboring the potential for a new cancer stem cell targeted therapy in ECC.

\section{Experimental Procedures}

\subsection{Cell Lines and Culture Conditions}

Monolayer cultures of three established pancreatic cancer cell lines (Panc-1, Capan, ASPC) and two distal cholangiocarcinoma cell lines (EGI, TFK) were cultured in RPMI 1640 medium (Gibco, Berlin, Germany) supplemented with 10\% 
fetal bovine serum (FBS superior, Gibco), penicillin (10.000 U/ml, Gibco), streptomycin $(10.000 \mu \mathrm{g} / \mathrm{ml}$, Gibco) and cotrimoxazole $(480 \mathrm{mg} / 5 \mathrm{ml}$, Ratiopharm, Ulm, Germany). All cells were incubated at $37^{\circ}$ in humidified air containing $5 \% \mathrm{CO}_{2}$.

\subsection{Flow Cytometry Analysis}

Cells were harvested by trypsinization. For side population staining, Hoechst-33342 dye was added at a concentration of $5 \mu \mathrm{l} / \mathrm{ml} / 10^{6}$ cells $/ \mathrm{ml}$ and cells were incubated for 90 minutes at $37^{\circ}$ in darkness. Negative controls were incubated with $4 \mu \mathrm{l} / \mathrm{ml}$ verapamil hydrochloride (Sigma Aldrich, St. Louis, USA) dissolved in distilled water simultaneously. After washing with PBS, Antibodies were added at a dilution of 1:249.5 (Notch1, Cell Signaling Technology, Danvers, USA) 1:65.33 (Notch 4, BioLegend, San Diego, USA), 1:28.94 (Adam 17, Antikoerper online), 1:30.18 (Musashi, Antikoerper online) and 1:33.89 (Hes 1, St. John's Laboratory, London, UK) for antibody staining. Samples were incubated at $4^{\circ}$ for $15 \mathrm{mi}-$ nutes, then washed with PBS and incubated with APC conjugated secondary antibody (Antikoerper online) at $4^{\circ}$. This procedure was performed earlier by Goodell et al. [30].

For DAPT- and Gemcitabine treatment experiments, $2 \times 10^{5}$ cells were seeded into clear 12 well plates (Falcon, New York, USA). 24 hours after seeding, the cells were treated with 10, 30, $50 \mu \mathrm{M}$ gamma secretase inhibitor DAPT (Sigma Aldrich, dissolved in dimethyl sulfoxide) or $50 \mu \mathrm{M}$ Gemcitabine ( $1 \mathrm{mg} / \mathrm{ml}) .48$ hours after treatment, cells were harvested, Hoechst-dyed and washed as described above.

Flow cytometry was quantified by FACS LSRII and analysed by FlowJo as described previously [31]. UV filters (675/50 635LP and 450/50 420LP) were used to identify the Hoecht-3342 staining, afterwards voltages and gates were determined based on the unstained- and negative control (Figure 6). PJ staining was used during the establishment to acquire the viability of the cell suspension. Experiments were repeated at least four times.
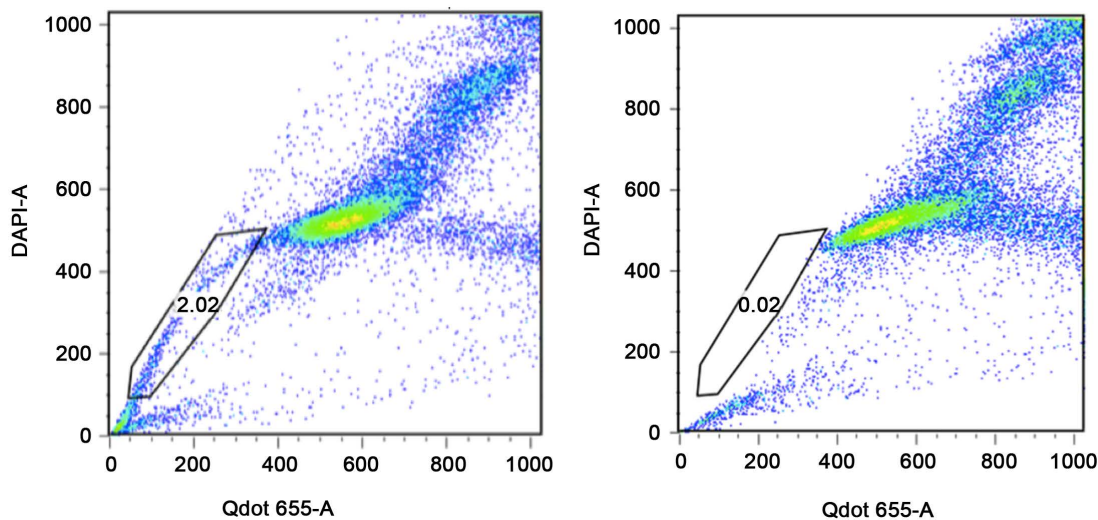

Figure 6. Original FCM image of Hoechst 33342 staining, including the gating of the SP-Population (left, 2.2\%) based on verapamil negative control (right). 


\subsection{CellTox Green Cytotoxity Assay}

The cytotoxic effect of the gamma secretase Inhibitor DAPT and Gemcitabine on cell lines was evaluated using the CellTox Green Cytotoxity Assay Kit (Promega, Madison, USA), which measures changes in membrane integrity as a result of cell destruction.

Cells $\left(2 \times 10^{3} /\right.$ well $)$ were cultured for 24 hours (approx. 80\% confluence) at the above mentioned conditions. In the next step, CellTox Green dye solution (1:500) as well as $5,10,30,50 \mu \mathrm{M}$ DAPT or $10,50,100,500,1000 \mu \mathrm{M}$ Gemcitabine were added to the wells. The experiments were performed according to the manufacturers instructions. The sensitivity of the CellTox Green Kit was tested according to the protocol and was detected with $>95 \%$. The cytotoxity of DAPT and Gemcitabine was quantified through Optima Plate Reader with $492 \mathrm{~nm}$ excitation and $520 \mathrm{~nm}$ emission at time point 0, 24 hours (time point 23 - 25) and 48 hours (time point 47 - 49) after treatment. Experiments were repeated at least three times.

\subsection{TUNEL-Staining}

For TUNEL staining, in Situ Cell Death Detection Kit TMR red (Roche, Basel, Switzerland) was used to determine apoptosis. This enzyme-driven labeling shows specific DNA breaks that develop in the early state of apoptosis.

Cell lines were seeded in black 96-well plates with a clear bottom (Greiner Bio One, Kremsmünster, Austria) at a density of $1.5 \times 10^{3}$ cells per well, and grown under the abovementioned conditions overnight. On the following day, the cells were incubated with medium supplemented with the following concentrations of therapeutics: 5, 10, 30, $50 \mu \mathrm{M}$ DAPT or 10, 50, 100, 500, $1000 \mu \mathrm{M}$ Gemcitabine for a total of 48 hours. The cells were then fixed using $4 \%$ formalin and stained following the manufacturers instructions.

After staining, the cell nuclei were visualized using fluorescent microscopy (Keyence, Osaka, Japan) and counted manually. Experiments were repeated at least three times.

\subsection{Statistical Analysis}

Statistical analysis was performed using GraphPad Prism software (Prism 6 for Macintosh, version 6.0e, GraphPad Software, La Jolla, USA). Data distribution was evaluated for normality using D'agostino and Pearson Omnibus tests. Furthermore, a student's t-test was applied to compare normally distributed data sets and a Mann-Whitney test for used to compare not normally distributed data set. A one-way analysis of variance (One-Way ANOVA) or a Kruskal-Wallis-test was used to compare multiple groups for statistical significance, followed by post-hoc test (Tukey's and Dunn's) for confirmation. To assess the difference of multiple independent variables, a two-way analysis of variance (two-way ANOVA) followed by the post-hoc test (Tukey's) for confirmation, was used. P $<0.05$ was considered as statistically significant. 


\section{References}

[1] Bailey, J.M., DelGiorno, K.E. and Crawford, H.C. (2014) The Secret Origins and Surprising Fates of Pancreas Tumors. Carcinogenesis, 35, 1436-1440. https://doi.org/10.1093/carcin/bgu056

[2] Razumilava, N. and Gores, G.J. (2013) Classification, Diagnosis, and Management of Cholangiocarcinoma. Clinical Gastroenterology and Hepatology: The Official Clinical Practice Journal of the American Gastroenterological Association, 11, 13-21.

[3] Seufferlein, T., Porzner, M., Heinemann, V., Tannapfel, A., Stuschke, M. and Uhl, W. (2014) Ductal Pancreatic Adenocarcinoma. Deutsches Arzteblatt International, 111, 396-402. https://doi.org/10.3238/arztebl.2014.0396

[4] Schmuck, R.B., de Carvalho-Fischer, C.V., Neumann, C., Pratschke, J. and Bahra, M. (2016) Distal Bile Duct Carcinomas and Pancreatic Ductal Adenocarcinomas: Postulating a Common Tumor Entity. Cancer Medicine, 5, 88-99. https://doi.org/10.1002/cam4.566

[5] Deshpande, V., Konstantinidis, I.T., Castillo, C.F., Hezel, A.F., Haigis, K.M., Ting, D.T., et al. (2016) Intra-Pancreatic Distal Bile Duct Carcinoma Is Morphologically, Genetically, and Clinically Distinct from Pancreatic Ductal Adenocarcinoma. Journal of Gastrointestinal Surgery, 20, 953-959.

[6] Conroy, T., Desseigne, F., Ychou, M., Bouche, O., Guimbaud, R., Becouarn, Y., et al. (2011) FOLFIRINOX versus Gemcitabine for Metastatic Pancreatic Cancer. The New England Journal of Medicine, 364, 1817-1825. https://doi.org/10.1056/NEJMoa1011923

[7] Von Hoff, D.D., Ervin, T., Arena, F.P., Chiorean, E.G., Infante, J., Moore, M., et al. (2013) Increased Survival in Pancreatic Cancer with Nab-Paclitaxel plus Gemcitabine. The New England Journal of Medicine, 369, 1691-1703. https://doi.org/10.1056/NEJMoa1304369

[8] Tirino, V., Desiderio, V., Paino, F., De Rosa, A., Papaccio, F., La Noce, M., et al. (2013) Cancer Stem Cells in Solid Tumors: An Overview and New Approaches for Their Isolation and Characterization. FASEB Journal, 27, 13-24. https://doi.org/10.1096/fj.12-218222

[9] Wang, X., Liu, Q., Hou, B., Zhang, W., Yan, M., Jia, H., et al. (2013) Concomitant Targeting of Multiple Key Transcription Factors Effectively Disrupts Cancer Stem Cells Enriched in Side Population of Human Pancreatic Cancer Cells. PLoS ONE, 8, e73942.

[10] Bolos, V., Grego-Bessa, J. and de la Pompa, J.L. (2007) Notch Signaling in Development and Cancer. Endocrine Reviews, 28, 339-363.

https://doi.org/10.1210/er.2006-0046

[11] Vaccaro, V., Melisi, D., Bria, E., Cuppone, F., Ciuffreda, L., Pino, M.S., et al. (2011) Emerging Pathways and Future Targets for the Molecular Therapy of Pancreatic Cancer. Expert Opinion on Therapeutic Targets, 15, 1183-1196. https://doi.org/10.1517/14728222.2011.607438

[12] Nakanuma, Y. (2010) A Novel Approach to Biliary Tract Pathology Based on Similarities to Pancreatic Counterparts: Is the Biliary Tract an Incomplete Pancreas? Pathology International, 60, 419-429. https://doi.org/10.1111/j.1440-1827.2010.02543.x

[13] Oettle, H., Neuhaus, P., Hochhaus, A., Hartmann, J.T., Gellert, K., Ridwelski, K., et al. (2013) Adjuvant Chemotherapy with Gemcitabine and Long-Term Outcomes 
among Patients with Resected Pancreatic Cancer: The CONKO-001 Randomized Trial. JAMA, 310, 1473-1481. https://doi.org/10.1001/jama.2013.279201

[14] Sinn, M.B.M., Denecke, T., Travis, S., Pelzer, U. and Riess, H. (2016) Perioperative Treatment Options in Resectable Pancreatic Cancer-How to Improve Long-Term Survival. World Journal of Gastrointestinal Oncology, 8, 248-257. https://doi.org/10.4251/wjgo.v8.i3.248

[15] Plentz, R., Park, J.S., Rhim, A.D., Abravanel, D., Hezel, A.F., Sharma, S.V., et al. (2009) Inhibition of Gamma-Secretase Activity Inhibits Tumor Progression in a Mouse Model of Pancreatic Ductal Adenocarcinoma. Gastroenterology, 136, 1741-1749e6.

[16] Mullendore, M.E., Koorstra, J.B., Li, Y.M., Offerhaus, G.J., Fan, X., Henderson, C.M., et al. (2009) Ligand-Dependent Notch Signaling Is Involved in Tumor Initiation and Tumor Maintenance in Pancreatic Cancer. Clinical Cancer Research, 15, 2291-2301. https://doi.org/10.1158/1078-0432.CCR-08-2004

[17] Kang, M., Jiang, B., Xu, B., Lu, W., Guo, Q., Xie, Q., et al. (2013) Delta like Ligand 4 Induces Impaired Chemo-Drug Delivery and Enhanced Chemoresistance in Pancreatic Cancer. Cancer Letters, 330, 11-21. https://doi.org/10.1016/j.canlet.2012.11.015

[18] Mazur, P.K., Einwachter, H., Lee, M., Sipos, B., Nakhai, H., Rad, R., et al. (2010) Notch2 Is Required for Progression of Pancreatic Intraepithelial Neoplasia and Development of Pancreatic Ductal Adenocarcinoma. Proceedings of the National Academy of Sciences of the United States of America, 107, 13438-13443. https://doi.org/10.1073/pnas.1002423107

[19] Riedlinger, D., Bahra, M., Boas-Knoop, S., Lippert, S., Bradtmoller, M., Guse, K., et al. (2014) Hedgehog Pathway as a Potential Treatment Target in Human Cholangiocarcinoma. Journal of Hepato-Biliary-Pancreatic Sciences, 21, 607-615. https://doi.org/10.1002/jhbp.107

[20] Hao, K., Tian, X.D., Qin, C.F., Xie, X.H. and Yang, Y.M. (2013) Hedgehog Signaling Pathway Regulates Human Pancreatic Cancer Cell Proliferation and Metastasis. Oncology Reports, 29, 1124-1132. https://doi.org/10.3892/or.2012.2210

[21] El Khatib, M., Bozko, P., Palagani, V., Malek, N.P., Wilkens, L. and Plentz, R.R. (2013) Activation of Notch Signaling Is Required for Cholangiocarcinoma Progression and Is Enhanced by Inactivation of p53 in Vivo. PLOS ONE, 8, e77433.

[22] Lee, J.Y., Song, S.Y. and Park, J.Y. (2014) Notch Pathway Activation Is Associated with Pancreatic Cancer Treatment Failure. Pancreatology, 14, 48-53. https://doi.org/10.1016/j.pan.2013.11.011

[23] Ostroukhova, M., Qi, Z., Oriss, T.B., Dixon-McCarthy, B., Ray, P. and Ray, A. (2006) Treg-Mediated Immunosuppression Involves Activation of the Notch-HES1 Axis by Membrane-Bound TGF-Beta. The Journal of Clinical Investigation, 116, 996-1004. https://doi.org/10.1172/JCI26490

[24] Kared, H., Adle-Biassette, H., Fois, E., Masson, A., Bach, J.F., Chatenoud, L., et al. (2006) Jagged2-Expressing Hematopoietic Progenitors Promote Regulatory T Cell Expansion in the Periphery through Notch Signaling. Immunity, 25, 823-834. https://doi.org/10.1016/j.immuni.2006.09.008

[25] Cook, N., Frese, K.K., Bapiro, T.E., Jacobetz, M.A., Gopinathan, A., Miller, J.L., et al. (2012) Gamma Secretase Inhibition Promotes Hypoxic Necrosis in Mouse Pancreatic Ductal Adenocarcinoma. The Journal of Experimental Medicine, 209, 437-444. https://doi.org/10.1084/jem.20111923

[26] Yabuuchi, S., Pai, S.G., Campbell, N.R., de Wilde, R.F., De Oliveira, E., Korangath, 
P., et al. (2013) Notch Signaling Pathway Targeted Therapy Suppresses Tumor Progression and Metastatic Spread in Pancreatic Cancer. Cancer Letters, 335, 41-51. https://doi.org/10.1016/j.canlet.2013.01.054

[27] Krop, I., Demuth, T., Guthrie, T., Wen, P.Y., Mason, W.P., Chinnaiyan, P., et al. (2012) Phase I Pharmacologic and Pharmacodynamic Study of the Gamma Secretase (Notch) Inhibitor MK-0752 in Adult Patients with Advanced Solid Tumors. Journal of Clinical Oncology, 30, 2307-2313.

[28] Tolcher, A.W., Messersmith, W.A., Mikulski, S.M., Papadopoulos, K.P., Kwak, E.L., Gibbon, D.G., et al. (2012) Phase I Study of RO4929097, a Gamma Secretase Inhibitor of Notch Signaling, in Patients with Refractory Metastatic or Locally Advanced Solid Tumors. Journal of Clinical Oncology, 30, 2348-2353.

https://doi.org/10.1200/JCO.2011.36.8282

[29] Messersmith, W.A., Shapiro, G.I., Cleary, J.M., Jimeno, A., Dasari, A., Huang, B., et al. (2015) A Phase I, Dose-Finding Study in Patients with Advanced Solid Malignancies of the Oral Gamma-Secretase Inhibitor PF-03084014. Clinical Cancer Research, 21, 60-67. https://doi.org/10.1158/1078-0432.CCR-14-0607

[30] Goodell, M.A. (2005) Stem Cell Identification and Sorting Using the Hoechst 33342 Side Population (SP). Current Protocols in Cytometry, Chapter 9, Unit 9, 18.

[31] Herzenberg, J., Moore, W.A., Herzenberg, L.A. and Parks, D.R. (2006) Interpreting Flow Cytometry Data: A Guide for the Perplexed. Nature Immunology, 7, 681-685. 


\section{Supplement}

Table S1. Dunnett's multiple comparisons test of Notch signaling pathway associated Antibodies in cell lines Panc1, ASPC and Capan, analysed by FCM.

\begin{tabular}{|c|c|c|c|}
\hline Cell line, Antibody & Mean Diff. & Adjusted P Value & SE of diff. \\
\hline \multicolumn{4}{|l|}{ Panc1 } \\
\hline Hoechst vs. Notch1 SP & -7.675 & 0.6798 & 5.372 \\
\hline Hoechst vs. Notch1 Non SP & -9.808 & 0.3906 & 5.372 \\
\hline Hoechst vs. Notch4 SP & -4.208 & 0.9884 & 5.372 \\
\hline Hoechst vs. Notch4 Non SP & -8.438 & 0.5713 & 5.372 \\
\hline Hoechst vs. ADAM17 SP & -3.865 & 0.9917 & 5.372 \\
\hline Hoechst vs. ADAM17 NonSP & -8.008 & 0.6325 & 5.372 \\
\hline Hoechst vs. Musashi SP & -1.775 & 0.9996 & 5.372 \\
\hline Hoechst vs. Musashi Non SP & -12.07 & 0.1771 & 5.372 \\
\hline Hoechst vs. Hes1 SP & -0.3330 & $>0.9999$ & 5.372 \\
\hline Hoechst vs. Hes1 Non SP & -8.978 & 0.4968 & 5.372 \\
\hline \multicolumn{4}{|l|}{ ASPC } \\
\hline Hoechst vs. Notch1 SP & 1.510 & 0.9997 & 5.885 \\
\hline Hoechst vs. Notch1 Non SP & -0.4880 & 0.9999 & 5.885 \\
\hline Hoechst vs. Notch4 SP & 0.1060 & $>0.9999$ & 5.885 \\
\hline Hoechst vs. Notch4 Non SP & -3.272 & 0.9991 & 5.885 \\
\hline Hoechst vs. ADAM17 SP & -1.612 & 0.9996 & 5.885 \\
\hline Hoechst vs. ADAM17 NonSP & -1.758 & 0.9996 & 5.885 \\
\hline Hoechst vs. Musashi SP & -0.1760 & $>0.9999$ & 5.885 \\
\hline Hoechst vs. Musashi Non SP & -1.994 & 0.9995 & 5.885 \\
\hline Hoechst vs. Hes1 SP & 1.722 & 0.9996 & 5.885 \\
\hline Hoechst vs. Hes1 Non SP & -0.3280 & $>0.9999$ & 5.885 \\
\hline \multicolumn{4}{|l|}{ Capan } \\
\hline Hoechst vs. Notch1 SP & 0.9750 & 0.9998 & 6.580 \\
\hline Hoechst vs. Notch1 Non SP & -0.9780 & 0.9998 & 6.580 \\
\hline Hoechst vs. Notch4 SP & -1.203 & 0.9997 & 6.580 \\
\hline Hoechst vs. Notch4 Non SP & -4.273 & 0.9960 & 6.580 \\
\hline Hoechst vs. ADAM17 SP & 1.193 & 0.9997 & 6.580 \\
\hline Hoechst vs. ADAM17 NonSP & -2.118 & 0.9996 & 6.580 \\
\hline Hoechst vs. Musashi SP & -0.7500 & 0.9999 & 6.580 \\
\hline Hoechst vs. Musashi Non SP & -2.523 & 0.9994 & 6.580 \\
\hline Hoechst vs. Hes1 SP & 1.210 & 0.9997 & 6.580 \\
\hline Hoechst vs. Hes1 Non SP & 0.4125 & $>0.9999$ & 6.580 \\
\hline
\end{tabular}


Table S2. Dunnett's multiple comparisons test of gemcitabine-treated cell lines Panc1, ASPC and TFK, examined in Cell Tox Green Cytotoxity assay.

\begin{tabular}{|c|c|c|c|}
\hline Cell line, time point, concentration & Mean Diff. & Adjusted P Value & SE of diff. \\
\hline \multicolumn{4}{|l|}{ Panc1 } \\
\hline \multicolumn{4}{|l|}{0} \\
\hline Control vs. Gemcitabin $10 \mu \mathrm{M}$ & 213.5 & 0.9676 & 367.0 \\
\hline Control vs. Gemcitabin $50 \mu \mathrm{M}$ & 123.5 & 0.9968 & 367.0 \\
\hline Control vs. Gemcitabin $100 \mu \mathrm{M}$ & 194.0 & 0.9783 & 367.0 \\
\hline Control vs. Gemcitabin $500 \mu \mathrm{M}$ & 301.3 & 0.8797 & 367.0 \\
\hline Control vs. Gemcitabin $1000 \mu \mathrm{M}$ & 328.8 & 0.8390 & 367.0 \\
\hline \multicolumn{4}{|l|}{23} \\
\hline Control vs. Gemcitabin $1 \mu \mathrm{M}$ & -14.00 & $>0.9999$ & 367.0 \\
\hline Control vs. Gemcitabin $50 \mu \mathrm{M}$ & -210.0 & 0.9698 & 367.0 \\
\hline Control vs. Gemcitabin $100 \mu \mathrm{M}$ & -40.50 & 0.9999 & 367.0 \\
\hline Control vs. Gemcitabin $500 \mu \mathrm{M}$ & -165.8 & 0.9892 & 367.0 \\
\hline Control vs. Gemcitabin $1000 \mu \mathrm{M}$ & -114.3 & 0.9980 & 367.0 \\
\hline \multicolumn{4}{|l|}{24} \\
\hline Control vs. Gemcitabin $10 \mu \mathrm{M}$ & -81.00 & 0.9997 & 423.8 \\
\hline Control vs. Gemcitabin $50 \mu \mathrm{M}$ & -214.7 & 0.9819 & 423.8 \\
\hline Control vs. Gemcitabin $100 \mu \mathrm{M}$ & 16.67 & $>0.9999$ & 423.8 \\
\hline Control vs. Gemcitabin $500 \mu \mathrm{M}$ & -133.3 & 0.9979 & 423.8 \\
\hline Control vs. Gemcitabin $1000 \mu \mathrm{M}$ & -123.0 & 0.9983 & 423.8 \\
\hline \multicolumn{4}{|l|}{25} \\
\hline Control vs. Gemcitabin $10 \mu \mathrm{M}$ & -156.8 & 0.9918 & 367.0 \\
\hline Control vs. Gemcitabin $50 \mu \mathrm{M}$ & -204.5 & 0.9729 & 367.0 \\
\hline Control vs. Gemcitabin $100 \mu \mathrm{M}$ & -130.5 & 0.9961 & 367.0 \\
\hline Control vs. Gemcitabin $500 \mu \mathrm{M}$ & -246.8 & 0.9421 & 367.0 \\
\hline Control vs. Gemcitabin $1000 \mu \mathrm{M}$ & -233.5 & 0.9534 & 367.0 \\
\hline \multicolumn{4}{|l|}{47} \\
\hline Control vs. Gemcitabin $10 \mu \mathrm{M}$ & -721.0 & 0.3069 & 423.8 \\
\hline Control vs. Gemcitabin $50 \mu \mathrm{M}$ & -949.0 & 0.1054 & 423.8 \\
\hline Control vs. Gemcitabin $100 \mu \mathrm{M}$ & -854.3 & 0.1699 & 423.8 \\
\hline Control vs. Gemcitabin $500 \mu \mathrm{M}$ & -1017 & 0.0728 & 423.8 \\
\hline Control vs. Gemcitabin $1000 \mu \mathrm{M}$ & -1275 & 0.0146 & 423.8 \\
\hline \multicolumn{4}{|l|}{48} \\
\hline Control vs. Gemcitabin $10 \mu \mathrm{M}$ & -531.8 & 0.4585 & 367.0 \\
\hline Control vs. Gemcitabin $50 \mu \mathrm{M}$ & -1312 & 0.0025 & 367.0 \\
\hline Control vs. Gemcitabin $100 \mu \mathrm{M}$ & -772.5 & 0.1413 & 367.0 \\
\hline Control vs. Gemcitabin $500 \mu \mathrm{M}$ & -1303 & 0.0027 & 367.0 \\
\hline Control vs. Gemcitabin $1000 \mu \mathrm{M}$ & -947.5 & 0.0465 & 367.0 \\
\hline
\end{tabular}




\section{Continued}

49

Control vs. Gemcitabin $10 \mu \mathrm{M}$

Control vs. Gemcitabin $50 \mu \mathrm{M}$

Control vs. Gemcitabin $100 \mu \mathrm{M}$

Control vs. Gemcitabin $500 \mu \mathrm{M}$

Control vs. Gemcitabin $1000 \mu \mathrm{M}$

ASPC

Control vs. Gemcitabin $10 \mu \mathrm{M}$

60.2560 .25

169.8

Control vs. Gemcitabin $50 \mu \mathrm{M}$

Control vs. Gemcitabin $100 \mu \mathrm{M}$

Control vs. Gemcitabin $500 \mu \mathrm{M}$

Control vs. Gemcitabin $1000 \mu \mathrm{M}$

23

Control vs. Gemcitabin $10 \mu \mathrm{M}$

Control vs. Gemcitabin $50 \mu \mathrm{M}$

Control vs. Gemcitabin $100 \mu \mathrm{M}$

Control vs. Gemcitabin $500 \mu \mathrm{M}$

Control vs. Gemcitabin $1000 \mu \mathrm{M}$

24

Control vs. Gemcitabin $10 \mu \mathrm{M}$

Control vs. Gemcitabin $50 \mu \mathrm{M}$

Control vs. Gemcitabin $100 \mu \mathrm{M}$

Control vs. Gemcitabin $500 \mu \mathrm{M}$

Control vs. Gemcitabin $1000 \mu \mathrm{M}$

25

Control vs. Gemcitabin $10 \mu \mathrm{M}$

Control vs. Gemcitabin $50 \mu \mathrm{M}$

Control vs. Gemcitabin $100 \mu \mathrm{M}$

Control vs. Gemcitabin $500 \mu \mathrm{M}$

Control vs. Gemcitabin $1000 \mu \mathrm{M}$

47

Control vs. Gemcitabin $10 \mu \mathrm{M}$

Control vs. Gemcitabin $50 \mu \mathrm{M}$

Control vs. Gemcitabin $100 \mu \mathrm{M}$

Control vs. Gemcitabin $500 \mu \mathrm{M}$

Control vs. Gemcitabin $1000 \mu \mathrm{M}$

$-785.0$

$-1719$

$-683.0$

$-1656$

$-883.5$

152.3

78.75

109.5

$-203.0$

$-157.5$

$-160.8$

$-232.3$

$-227.3$

$-275.8$

$-165.3$

$-199.0$

$-284.5$

$-357.0$

$-269.3$

$-198.3$

$-257.8$

$-373.3$

$-485.3$

$-1614$

$-1947$

$-2620$

$-2740$

$-1889$
0.4173

519.0

0.0058

519.0

0.5505

519.0

0.0085

519.0

0.3064

519.0

0.9899

455.8

0.9965

455.8

0.9962

455.8

0.9815

455.8

0.9831

455.8

0.9621

455.8

0.9958

455.8

0.9908

455.8

0.9569

455.8

0.8979

455.8

0.9655

455.8

0.9910

455.8

0.9712

455.8

0.8808

455.8

0.7304

455.8

0.0121

526.4

0.0016

526.4

$<0.0001$

526.4

$<0.0001$

526.4

0.0024 


\section{Continued}

48

Control vs. Gemcitabin $10 \mu \mathrm{M}$

$-1457$

$-2447$

$-2791$

Control vs. Gemcitabin $100 \mu \mathrm{M}$

Control vs. Gemcitabin $500 \mu \mathrm{M}$

Control vs. Gemcitabin $1000 \mu \mathrm{M}$

49

Control vs. Gemcitabin $10 \mu \mathrm{M}$

Control vs. Gemcitabin $50 \mu \mathrm{M}$

Control vs. Gemcitabin $100 \mu \mathrm{M}$

Control vs. Gemcitabin $500 \mu \mathrm{M}$

Control vs. Gemcitabin $1000 \mu \mathrm{M}$

TFK

$$
0
$$

Control vs. Gemcitabin $10 \mu \mathrm{M}$

Control vs. Gemcitabin $50 \mu \mathrm{M}$

Control vs. Gemcitabin $100 \mu \mathrm{M}$

Control vs. Gemcitabin $500 \mu \mathrm{M}$

Control vs. Gemcitabin $1000 \mu \mathrm{M}$

23

Control vs. Gemcitabin $10 \mu \mathrm{M}$

Control vs. Gemcitabin $50 \mu \mathrm{M}$

Control vs. Gemcitabin $100 \mu \mathrm{M}$

Control vs. Gemcitabin $500 \mu \mathrm{M}$

Control vs. Gemcitabin $1000 \mu \mathrm{M}$

Control vs. Gemcitabin $10 \mu \mathrm{M}$

Control vs. Gemcitabin $50 \mu \mathrm{M}$

Control vs. Gemcitabin $100 \mu \mathrm{M}$

Control vs. Gemcitabin $500 \mu \mathrm{M}$

Control vs. Gemcitabin $1000 \mu \mathrm{M}$

25

Control vs. Gemcitabin $10 \mu \mathrm{M}$

Control vs. Gemcitabin $50 \mu \mathrm{M}$

Control vs. Gemcitabin $100 \mu \mathrm{M}$

Control vs. Gemcitabin $500 \mu \mathrm{M}$

Control vs. Gemcitabin $1000 \mu \mathrm{M}$
51.25

$-354.5$

$-583.5$

$-530.0$

$-330.5$

$-63.00$

$-5.750$

$-87.75$

$-15.00$

$-54.00$

149.0

84.00

$-37.67$

56.33

72.67

$-55.33$

3.667

11.67

$-25.33$

$-19.33$

$0.0283 \quad 526.4$

$\begin{array}{ll}<0.0001 & 526.4\end{array}$

$<0.0001 \quad 526.4$

$-3046 \quad<0.0001$

$\begin{array}{lll}-1600 & 0.0131 & 526.4\end{array}$

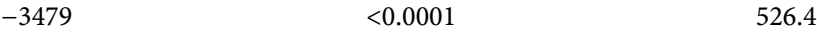

$\begin{array}{lll}-1851 & 0.0030 & 526.4\end{array}$

$\begin{array}{ll}-2628 & <0.0001\end{array}$

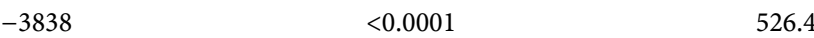

$-2937<0.0001<526.4$

$>0.9999$

810.6

0.9907

0.9249

0.9480

0.9933

0.9999

810.6

$>0.9999$

810.6

0.9999

$>0.9999$

810.6

810.6

810.6

0.9997

936.0

0.9999

936.0

$>0.9999$

936.0

$>0.9999$

936.0

0.9999

936.0

936.0

936.0

936.0

$>0.9999$

936.0

$>0.9999$

936.0 


\section{Continued}

47

Control vs. Gemcitabin $10 \mu \mathrm{M}$

Control vs. Gemcitabin $50 \mu \mathrm{M}$

Control vs. Gemcitabin $100 \mu \mathrm{M}$

Control vs. Gemcitabin $500 \mu \mathrm{M}$

Control vs. Gemcitabin $1000 \mu \mathrm{M}$

48

Control vs. Gemcitabin $10 \mu \mathrm{M}$

Control vs. Gemcitabin $50 \mu \mathrm{M}$

Control vs. Gemcitabin $100 \mu \mathrm{M}$

Control vs. Gemcitabin $500 \mu \mathrm{M}$

Control vs. Gemcitabin $1000 \mu \mathrm{M}$

49

Control vs. Gemcitabin $10 \mu \mathrm{M}$

Control vs. Gemcitabin $50 \mu \mathrm{M}$

Control vs. Gemcitabin $100 \mu \mathrm{M}$

Control vs. Gemcitabin $500 \mu \mathrm{M}$

Control vs. Gemcitabin $1000 \mu \mathrm{M}$
$-474.5$

$-699.0$

$-3014$

$-1829$

$-2386$

$-2356$

$-2112$

$-3688$

$-2762$

$-1618$

0.2937

0.0432

0.0013

0.0007

0.1077
1146

1146

1146

1146

1146

936.0

936.0

936.0

936.0

936.0

936.0

936.0

936.0

936.0

936.0

Table S3. Dunnett's multiple comparisons test of DAPT-treated PDAC cell line ASPC, TFK and EGI, examined in Cell Tox Green Cytotoxity assay.

\begin{tabular}{|c|c|c|c|}
\hline Cell line, time Point, concentration & Mean Diff. & Adjusted P Value & SE of diff. \\
\hline \multicolumn{4}{|l|}{ ASPC } \\
\hline \multicolumn{4}{|l|}{0} \\
\hline Control vs. DAPT $5 \mu \mathrm{M}$ & 125.5 & 0.9780 & 286.8 \\
\hline Control vs. DAPT $10 \mu \mathrm{M}$ & 76.00 & 0.9966 & 286.8 \\
\hline Control vs. DAPT $30 \mu \mathrm{M}$ & 178.3 & 0.9260 & 286.8 \\
\hline Control vs. DAPT $50 \mu \mathrm{M}$ & -3.000 & $>0.9999$ & 286.8 \\
\hline \multicolumn{4}{|l|}{23} \\
\hline Control vs. DAPT $5 \mu \mathrm{M}$ & -145.0 & 0.9631 & 286.8 \\
\hline Control vs. DAPT $10 \mu \mathrm{M}$ & -157.8 & 0.9507 & 286.8 \\
\hline Control vs. DAPT $30 \mu \mathrm{M}$ & -181.5 & 0.9215 & 286.8 \\
\hline Control vs. DAPT $50 \mu \mathrm{M}$ & -364.5 & 0.5207 & 286.8 \\
\hline \multicolumn{4}{|l|}{24} \\
\hline Control vs. DAPT $5 \mu \mathrm{M}$ & -149.8 & 0.9587 & 286.8 \\
\hline Control vs. DAPT $10 \mu \mathrm{M}$ & -183.8 & 0.9184 & 286.8 \\
\hline Control vs. DAPT $30 \mu \mathrm{M}$ & -205.0 & 0.8851 & 286.8 \\
\hline Control vs. DAPT $50 \mu \mathrm{M}$ & -387.8 & 0.4661 & 286.8 \\
\hline
\end{tabular}




\section{Continued}

25

Control vs. DAPT $5 \mu \mathrm{M}$

Control vs. DAPT $10 \mu \mathrm{M}$

Control vs. DAPT $30 \mu \mathrm{M}$

Control vs. DAPT $50 \mu \mathrm{M}$

$$
47
$$

Control vs. DAPT $5 \mu \mathrm{M}$

Control vs. DAPT $10 \mu \mathrm{M}$

Control vs. DAPT $30 \mu \mathrm{M}$

Control vs. DAPT $50 \mu \mathrm{M}$

48

Control vs. DAPT $5 \mu \mathrm{M}$

Control vs. DAPT $10 \mu \mathrm{M}$

Control vs. DAPT $30 \mu \mathrm{M}$

Control vs. DAPT $50 \mu \mathrm{M}$

49

Control vs. DAPT $5 \mu \mathrm{M}$

Control vs. DAPT $10 \mu \mathrm{M}$

Control vs. DAPT $30 \mu \mathrm{M}$

Control vs. DAPT $50 \mu \mathrm{M}$

TFK

0

Control vs. DAPT $5 \mu \mathrm{M}$

Control vs. DAPT $10 \mu \mathrm{M}$

Control vs. DAPT $30 \mu \mathrm{M}$

Control vs. DAPT $50 \mu \mathrm{M}$

23

Control vs. DAPT $5 \mu \mathrm{M}$

Control vs. DAPT $10 \mu \mathrm{M}$

Control vs. DAPT $30 \mu \mathrm{M}$

Control vs. DAPT $50 \mu \mathrm{M}$

Control vs. DAPT $5 \mu \mathrm{M}$

Control vs. DAPT $10 \mu \mathrm{M}$

Control vs. DAPT $30 \mu \mathrm{M}$

Control vs. DAPT $50 \mu \mathrm{M}$
$-198.0$

$-186.3$

$-239.8$

$-508.5$

$-25.33$

$-1008$

$-650.3$

$-894.0$

94.00

$-986.3$

$-564.3$

$-1025$

$-234.7$

$-1099$

$-637.7$

$-1629$

$-414.5$

$-789.3$

$-284.3$

$-291.8$

$-50.25$

$-47.50$

$-115.5$

$-275.0$

156.0

65.00

4.333

$-11.00$
0.8968

286.8

0.9148

286.8

0.8187

286.8

286.8

0.2341

0.9999

331.1

0.0111

331.1

0.1618

331.1

0.0289

331.1

0.9957

331.1

0.0134

331.1

0.2652

331.

0.0095

331.1

0.8881

331.1

0.0049

331.1

0.1747

331.1

$<0.0001$

331.1

0.7573

444.3

0.2342

444.3

0.9187

444.3

0.9117

444.3

444.3

444.3

444.3

444.3

0.9269

0.9944

513.0

0.9998

513.0

$>0.9999$

513.0

$>0.9999$

513.0 
25

Control vs. DAPT $5 \mu \mathrm{M}$

13.33

Control vs. DAPT $10 \mu \mathrm{M}$

$-47.33$

Control vs. DAPT $30 \mu \mathrm{M}$

Control vs. DAPT $50 \mu \mathrm{M}$

47

Control vs. DAPT $5 \mu \mathrm{M}$

Control vs. DAPT $10 \mu \mathrm{M}$

Control vs. DAPT $30 \mu \mathrm{M}$

Control vs. DAPT $50 \mu \mathrm{M}$

48

Control vs. DAPT $5 \mu \mathrm{M}$

Control vs. DAPT $10 \mu \mathrm{M}$

Control vs. DAPT $30 \mu \mathrm{M}$

Control vs. DAPT $50 \mu \mathrm{M}$

49

Control vs. DAPT $5 \mu \mathrm{M}$

Control vs. DAPT $10 \mu \mathrm{M}$

Control vs. DAPT $30 \mu \mathrm{M}$

Control vs. DAPT $50 \mu \mathrm{M}$

\section{EGI}

0

Control vs. DAPT 5mM

Control vs. DAPT 10mM

Control vs. DAPT 30mM

Control vs. DAPT 50mM

23

Control vs. DAPT $5 \mu \mathrm{M}$

Control vs. DAPT $10 \mu \mathrm{M}$

Control vs. DAPT $30 \mu \mathrm{M}$

Control vs. DAPT $50 \mu \mathrm{M}$

24

Control vs. DAPT $5 \mu \mathrm{M}$

Control vs. DAPT $10 \mu \mathrm{M}$

Control vs. DAPT $30 \mu \mathrm{M}$

Control vs. DAPT $50 \mu \mathrm{M}$
$-78.33$

$-329.7$

$-24.50$

348.0

27.50

$-768.0$

$-568.3$

$-718.3$

$-871.0$

$-1619$

$-363.0$

$-757.7$

$-1066$

$-1213$

$-534.0$

$-35.00$

$-34.25$

242.3

$-161.3$

$-201.5$

$-419.0$

$-541.8$

$-169.0$

$-174.5$

$-490.0$

$-452.8$
$>0.9999$

0.9999

0.9997

0.9175

$>0.9999$

0.9495

$>0.9999$

0.5554

0.6362

0.4359

0.2697

0.0084

0.8886

513.0

0.3885

513.0

0.1295

0.0684

513.0

513.0

0.9521

978.8

$>0.9999$

978.8

$>0.9999$

978.8

0.9973

978.8

0.9993

978.8

0.9987

978.8

0.9796

978.8

0.9497

978.8

978.8

978.8

0.9991

978.8

0.9644

0.9730 


\section{Continued}

Control vs. DAPT $5 \mu \mathrm{M}$

Control vs. DAPT $10 \mu \mathrm{M}$

Control vs. DAPT $30 \mu \mathrm{M}$

Control vs. DAPT $50 \mu \mathrm{M}$

47

Control vs. DAPT $5 \mu \mathrm{M}$

Control vs. DAPT $10 \mu \mathrm{M}$

Control vs. DAPT $30 \mu \mathrm{M}$

Control vs. DAPT $50 \mu \mathrm{M}$

48

Control vs. DAPT $5 \mu \mathrm{M}$

Control vs. DAPT $10 \mu \mathrm{M}$

Control vs. DAPT $30 \mu \mathrm{M}$

Control vs. DAPT $50 \mu \mathrm{M}$

49

Control vs. DAPT $5 \mu \mathrm{M}$

Control vs. DAPT $10 \mu \mathrm{M}$

Control vs. DAPT $30 \mu \mathrm{M}$

Control vs. DAPT $50 \mu \mathrm{M}$
187.8

0.0

$-55.50$

$-167.3$

$-1128$

$-486.5$

$-1459$

$-1660$

$-2416$

$-554.3$

$-1950$

$-1312$

$-3807$

$-946.5$

$-3323$

$-1997$
0.9990

978.8

$>0.9999$

978.8

$>0.9999$

978.8

0.9992

978.8

0.6043

978.8

0.9652

978.8

0.3791

978.8

0.2693

978.8

0.1124

1130

0.9669

1130

0.2553

1130

0.5979

1130

0.0252

1384

0.8998

1384

0.0616

1384

0.4085

1384 